\title{
The United Nations Documents Collection at New York University
}

Dr. Chamberlin is professor of government, New York University; Miss Moor is in charge of the United Nations Collection of the N.Y.U. Library.

$\mathrm{T}$ HE United Nations Documents Collection at New York University represents an attempt to solve, by a combination of conventional and unconventional means, a number of problems that exist in all large libraries without decreasing the usefulness of the material and, where possible, making it more usable. The result has been to develop one of the most complete and usable collections of English language United $\mathrm{Na}$ tions documents in the world. The interest of scholars in the New York University collection, and the number of questions concerning it from librarians engaged in coping with the same vast material, were the reasons for preparing this account of the procedures used.

\section{Need For Collection}

The need for such a collection sprang from two sources: first, the decision of the university in 1947 to establish a Graduate Program of Studies in United Nations and World Affairs, and second, the realization that the United Nations and the specialized agencies were entering into the discussion and study of such a wide range of human activities that the documentation which would be produced would be useful to virtually every department and discipline in the university. The Graduate Program of Studies in United Nations and World
Affairs was designed to provide M.A. and $\mathrm{Ph}$.D. degrees that would permit candidates to cut across the usual departmental lines - a clear recognition that the United $\mathrm{Na}$ tions system would do the same. The physical proximity of the university to the headquarters of the United Nations presented unusual opportunities and unusual responsibilities to collect U.N. documents and to provide adequate facilities for the study of the international organization and its operations.

It was immediately recognized that one of the first steps required would be the creation of an exceptionally complete and usable documents collection. While the university had had global subscriptions for all published United Nations material, it had not undertaken to acquire the mimeographed papers. The decision to create such a collection was followed by investigation of collections of United Nations documents in other libraries. The number of instances found where libraries had extensive holdings, but where the material was virtually unusable, were numerous enough that the problem of making the future collection available and usable for library patrons was fully as important as acquiring the material in the first place.

\section{Three Year Plan}

Because, as is often the case in libraries, both funds and floor space were limited, it was decided to build the desired type of collection according to a "three-year plan," as outlined below : 
I948-i949 ACADEMic Year:

I. Acquire all the processed and printed English language documents of the United Nations.

2. Accession all documents and begin preparations for binding (this required that approximately 250,000 documents be sorted, arranged in symbol series, checked, missing numbers obtained or noted, and duplicates discarded).

3. Complete the binding of the printed United Nations publications already owned by the university.

I949-I950 ACADEMIC YeAR:

I. Bring the United Nations documents up to date, including accessioning, shelflisting and binding.

2. Start to acquire the documents of the specialized agencies on an extensive basis and process them in temporary form. (The university was already receiving the published documents of some agencies.)

3. Expand the collection of United States government documents relating to the United Nations system.

4. Merge the university's League of Nations documents with the United Nations documents after rechecking and reconditioning the former.

I950-195I ACADEMIC YeAR:

I. Continue the United Nations collection.

2. Continue the specialized agency collection and complete the accessioning and binding.

3. Continue the United States government collection.

4. Expand the collection of the documents of other governments which relate to the United Nations.

5. Start to acquire the papers of nongovernmental organizations whose work is relevant to the United Nations.

\section{Distinction Between Documents and Other Materials}

It will be noted that no mention has been made of books about the United Nations which are not published by the organization. A clear distinction was made between such books and periodicals, on the one hand, and documents on the other. Desirable as amalgamation of the two types of material relating to the same subject might be, the practical reality of space available made separation necessary. Certain advantages have accrued from the separation, notably, the development of a reference staff expert in its knowledge of primary source material. Thus the books and periodicals about the United Nations are not part of the collection and are cataloged and shelved in the usual manner.

\section{Space Provided}

When the decision to create the collection was made in the summer of 1948 , the printed publications of the United Nations were housed in the Serials Division and arrangements were concluded to acquire and process the mimeographed documents in another building. The separation of the two types of material was a matter of expediency, rather than choice. In the summer of 1949, extensive remodeling of the library's plant permitted the assignment of an alcove in the Serials Reading Room which made it possible to bring all the material together. This alcove has approximately 300 linear feet of shelving and space for a desk and two reading tables, with additional table space adjacent. A work room with 125 linear feet of shelving and large enough for a six-foot table has been provided nearby, thus making it possible to have room for sorting and other mechanical processes outside the stack-reading room area. It is estimated that the present available space will be adequate for the expanding collection through the summer of I95I, at which time the whole problem of the collection and its future will be surveyed.

\section{Staffing Arrangements}

To put this plan into operation in 1948 , two part-time students were employed, one 
a graduate student with some knowledge of United Nations documents and the other an undergraduate without such knowledge. The personnel was selected so that there would be continuity of trained staff to serve the collection. The undergraduate chosen was one who intended to continue on in graduate study leading to the Ph.D. degree and would presumably be available for two or more years. These two parttime students spent the first year in sorting, checking and listing the mimeographed material as fast as it was obtained. At the end of the year they had done the preliminary sorting and had begun the preparation of some volumes for binding. In the summer of 1949 it became evident that increased staff would be necessary to complete the sorting and arranging of the immense mass of mimeographed documentation obtained from friends and other institutions. The director of libraries and the librarian of the Washington Square Library approved the appointment of one fulltime and three part-time students for the academic year 1949-50 with a view to completing the sorting and processing of the approximately 250,000 items.

The full-time student, the former parttime undergraduate in $1948-49$ and the three half-time students completed the work on the backlog in June I950, and have also provided reference service to the users of the collection on a five and one-half day per week basis, including evenings until 8:30 P.M.

\section{Acquisitions}

The university maintains three global subscriptions for the published United $\mathrm{Na}$ tions material from the international documents service of the Columbia University Press and, in addition, receives one copy of all unrestricted mimeographed and printed documents by virtue of the gracious decision of the librarian of the United Nations that the university is one of the recognized centers for the study of international affairs. One of the subscription sets is deposited in the Law Library, one in the School of Commerce Library and the third in the United Nations Collection in the Serials Division of the Washington Square Library. It is this latter set, plus the free set of printed and mimeographed documents, which constitutes the collection described herein.

The three subscription sets are mailed to the Acquisition Division of the university's libraries, where they are checked against bills and accessioned before being distributed. The fourth set, that received directly from the United Nations, is picked up each morning at the United Nations building in New York City by the university's messenger and brought directly to the United Nations Collection.

'This fourth set is processed in a somewhat different manner from the other three because of the desire to have the current documents available for faculty and student use within 24 hours of the date of issue by the United Nations. Such a service is maintained because of the need for most recent information available by classes, seminars and faculty members engaged in research and because of the belief that processing that is to be done eventually can just as well be done currently and promptly. In other words, the policy is to avoid the creation of an anathema to all librarians, the backlog or the arrearage.

The result of this policy has been that in many instances, printed publications are available for users of the collection at the same time they are provided to official delegations and to members of the Secretariat of the United Nations. Numerous instances have occurred when the university has received publications in its free set as much as several weeks ahead of the general distribution to subscribers to United $\mathrm{Na}$ - 
tions documents. The benefit to those engaged in research on current problems is evident.

Materials received on this daily basis are listed on visible card files under the symbol or series in which they are issued. The printed items are then shelved according to the plan explained below, and the mimeographed documents are placed in fourdrawer vertical steel files, of which there are only two. The volume of papers maintained in vertical files is kept at a minimum by the binding policy observed, also explained below, and it is thought that two vertical files will continue to be adequate for all foreseeable needs.

\section{Binding}

The policy governing binding requires that the collection be maintained in usable condition at all times and that items should not be missing for any considerable period of time because they are "at the bindery." To meet such a standard, both from the point of view of budget and time, three processes are used.

The first is the normal commercial contract binding in full board and buckram, at the usual range of prices, ranging from $\$ 2.00$ upward per volume depending upon size and requirements determined by the librarian.

The second is a form of pamphlet binding which is done in the library by staff employed for this purpose.

The third binding process appears to be unusual, judging by the number of visitors to the collection whose only interest is in seeing the volumes so bound. Actually there is nothing new in the method, as it is simply an adaptation of the pad-binding used in manufacturing scratch pads or other stationery in pad form. The university

1 The quicker the documents kept in file follers can be bound, the less opportunity there is for pilferage and other forms of loss. adopted the method as the result of observance of its application by the Secretariat of the United Nations, where the deputy director of the Publications Division, D. D. DeWalt, had experimented for three years and had developed a very satisfactory inexpensive binding. The process is used primarily for the mimeographed documents but is not limited thereto, as it is adequate for any nonpermanent items. It is this method and the pamphlet binding which have made it possible to limit the current material maintained in vertical files to two fourdrawer cases.

The pad-binding is done in the university's duplicating shop at a cost of approximately $25 \%$ per volume. Twenty to 50 volumes are prepared for binding at one time and normally are not out of the collection more than 48 hours. Preparation for binding includes typing of a title page containing a list of the documents in the volume, and the removal of all staples. A $3^{\prime \prime} \times 5^{\prime \prime}$ card is then prepared as a binding record and serves as a shelffist card when the volume has been bound. The use of the one card for two purposes is possible because the instructions to the bindery are standard and do not vary from volume to volume.

The technique of pad-binding is simple. When the documents are received at the bindery, each volume is placed in a paper cutter and the binding edge is trimmed enough to insure that each sheet will touch the binding material. Pieces of pressboard cut to size, or trimmed to fit each volume as the case may be, are then placed on the front and back of the volume. The volumes, 20 or more, are then stacked one on top of another, with the binding edges true and square to one another. A layer of thick binders glue is then applied to the area of the binding edges of the stacked volumes in one application. If the documents to be 
bound are $1 \mathrm{O}^{\prime \prime}$ long and the 20 volumes average $I \frac{1}{2} "$ in thickness, the area to which the glue is applied by paint brush in one operation is 300 square inches, thus reducing the labor costs per volume. After the glue has been applied, a layer of cloth (crash) is applied to the glue, following which a second layer of glue is applied over the cloth. Heavy weights are then placed on top of the pile of volumes and they are allowed to dry overnight. If a press of sufficient capacity is available, it is used instead of the weights, but such a press is not required as the weight of the volumes supplies all the pressure necessary except to the few top items.

On the following day, the volumes with their pressboard covers are sliced apart with a sharp knife and vellum tape is placed over the spine of each volume, overlapping on each cover not less than one inch. The volumes are then returned to the collection and are ready for lettering and shelving. The experience at the United Nations and at the university leads to the belief that this form of binding will last as long as will the woodpulp paper used for mimeographed documents.

The pad-binding is an inexpensive process and requires no equipment or capital investment other than a paper cutter powerful enough to trim a volume that may be as much as 2" thick. All that is needed in addition is a homemade rack to hold the volumes while they are being glued and dried, plus the supplies of glue, crash, pressboard and vellum tape. The process is adaptable because of the small amount of floor space required. It should be understood that it is as easy to bind roo volumes at a time as it is to bind 20 ; in fact, it is cheaper per volume. The only limit is the height of the ceiling of the room in which the work is done.

\section{Shelving}

The documents are all shelved according to the documents symbol system of the United Nations. The decision to follow this course was dictated by the structure of the United Nations itself, which is in many ways a subject structure, and by the realization that most users of the documents would request them by name of organ or documentary series. The manner of shelving was closely related to the decision regarding cataloging, described in detail below. Thus all documents of the General Assembly are shelved together, all Secretariat documents are shelved together and all items bearing sales numbers are shelved together. Such a system is recognition of the fact that there are four principal categories of United Nations documents, though they sometimes cross and duplicate one another :

I. The printed official records of the main organs.

II. The mimeographed series (some individual items of which are occasionally printed in one or more of the other categories).

III. The Secretariat series.

IV. The sales series.

The documents not included in the sales series are shelved in the following order:

I. The United Nations Conference on International Organization
A. Printed 16 volumes
B. Mimeographed documents

II. Executive Committee of the Preparatory Commission of the United Nations (follows same general plan as under General Assembly below)

III. Preparatory Commission of the United Nations

IV. General Assembly by session in chronological order

A. Each session in this order

I. Index to session (if any)

2. Resolutions of each session (will 
he shifted to supplements to the official records for past session if the U.N. decides to print future resolutions in that subseries)

3. Plenary meeting documents

a. Printed official records

b. Printed official records annexes

c. Mimeographed verbatim records

d. Mimeographed summary records

e. Mimeographed A/- documents

4. General Committee documents

a. Printed official records

b. Printed official records annexes

c. Mimeographed summary records

d. Mimeographed A/-BUR documents

5. Documents of committees, I, 2,

$2 \& 3,4,5,6$ and sessional ad hoc committees in which all members are represented are shelved in the same manner as those of the general committee

a. Subcommittees and drafting subcommittees documentation are shelved at the end of the papers for the relevant committee for the session.

6. Supplements to the official records of each session

7. Documents of all other ad hoc bodies are shelved after the most recent sessional papers, because these documents are not sessional, for the most part, and originate from bodies meeting between sessions, and in some instances, meeting over a period of several regular sessions.

Essentially the same pattern is followed for the documents of the Economic and Social Council and the Trusteeship Council, both of which meet by sessions each year.

The Security Council and Atomic Energy Commission documentation also follows the same basic pattern, except that the documents are shelved by month of issue because the two bodies are theoretically in perma- nent session. The order on the shelves is as follows:

I. January printed official records

2. January printed official record annexes and supplements

3. January mimeographed verbatim records

4. January S/- documents

5. At the end of the Security Council Collection are shelved the documents of all ad hoc committees, subcommittees, field missions, etc.

The publications issued within the sales number series are shelved under such series because of the subject arrangement of the series themselves. Because adequate research tools prepared by the United Nations Secretariat are available as guides to this material, it is more usable when shelved in this manner than if broken up under some other system which would make the reference tools available relatively useless.

The Secretariat documentation, which is voluminous and cuts across virtually all subject fields used by the organization, is shelved according to the unified system of symbols recently adopted. Items issued before this unified system was in use are arbitrarily assigned to positions on the shelves in keeping with the new symbols.

\section{Cataloging (or Noncataloging)}

Very few of the documents in the United Nations Collection are cataloged, a sharp break with traditional practice which was not determined until all concerned had been consulted. There are four basic reasons upon which this decision was based:

1. The United Nations Secretariat has produced many excellent reference tools and checklists which go far beyond anything that any catalog can ever be expected to accomplish with the funds likely to be provided.

2. The arrearage in cataloging of United Nations documents by the Library of Congress, or anyone else, was so great as to make it unlikely that it could ever become 
current. (Perhaps an arrearage of as much as 40,000 documents in one language by the end of 1948.)

3. The inadequacy of any catalog as a guide to the best items on any subject within a large block of material of this nature.

4. Cost of cataloging and maintaining such a catalog, particularly in the light of the reference tools described in " $I$ " above.

The essential feature of the plan is that in place of the usual author, title or subject cards the catalog contains "see also" cards directing the user to the United $\mathrm{Na}$ tions Collection. One such card appears under the catalog entry, United Nations, in front of the cards for books about the United Nations which are not published by that organization. Subject cards are inserted throughout the catalog thus:

\section{HUMAN RIGHTS \\ see also \\ United Nations Collection in Serials Reading Room}

The users of the library are best served by being guided by the catalog to the reference staff of the collection where the wealth of reference tools are put at their disposal and where trained staff can assist them.

The operation of the plan may be described by explaining in some detail one example, although the method is equally applicable to any subject discussed or studied by the United Nations.

The average lower division student represents the level of user of documents whose needs are normally the simplest. Such a student, looking under the heading HumaN Rights, finds in the catalog only cards for items about the subject which are not issued by the United Nations. He also finds the "see also" card described above. If the non-United Nations publications are not adequate for his need, he proceeds to the United Nations Collection and explains that need to the librarian on duty. In all probability, he would be given a mimeographed document prepared by the Department of
Public Information of the Secretariat of the United Nations bearing the title, Commission on Human Rights, Background Paper no. 25, and simultaneously handed the volumes of the United Nations Bulletin. In many instances, these two items, or one of them, are adequate for his need. Yet neither would normally have been cataloged because of the ephemeral nature of the first as a processed document, and because analytics do not exist for the Bulletin. The student would not have been aware of the existence of either item and could not, therefore, have called for either. The result is that this student, with his limited interest or need, has left the library satisfied. Most important of all, perhaps, is the fact that he was supplied with the type of material best suited to his need and he was not required to leaf through a large number of cards while simultaneously attempting to form a judgment as to which item would best suit his need, a judgment that he had neither the experience nor training to make. This is not the place to discuss why he was not equipped to make such a judgment, and the procedure described herein was devised to meet the situation that exists.

Consider now the better lower-division student or the upper-division student engaged in the preparation of a term paper on "Human Rights." In this case, the initial approach to the catalog is the same as that of the first student, but the need is entirely different. One or two papers of a background character will not be sufficient. Yet neither should the student be forced to consider the whole range of material on the subject. This is particularly true when normal methods of cataloging would not direct him to a large segment of the most important material. Finally, reliance on the catalog may deprive the student of knowledge of the existence of excellent available tools of reference, obviously the first place to start his research. 
'The important United Nations documentation and publications on human rights are listed below in tabular form in order to give a graphic representation of the problem the potential user must face when he begins his search. The items listed are by

\section{United Nations Documents and Publications on "Human Rights"}

Reference tools

I. United Nations Documents Index

Check List of United Nations Documents :

2. Part I: General Assembly

3. Part 4: Trusteeship Council

4. Part 5: Economic and Social Council

5. Part 6D: Human Rights Commission

6. Part 6E: Social Commission

7. Part 6F: Commission on the Status of Women

8. A/INF papers

9. E/INF papers

Index Notes:

10. Cumulative Index to the Resolutions of the Economic and Social Council

I I. Cumulative Index to the Resolutions of the General Assembly

Documentation and publications

12. Human Rights Yearbook

13. Mimeographed papers of the Commission on Human Rights

Items which would usually: not be cata- be cataloged loged under under

Human Rights Human Rights

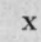

$\mathbf{x}$

$\mathrm{x}$

$\mathrm{x}$

General Assembly Official Records:

14. Plenary Meetings

I5. Resolutions

16. General Committee

I7. First Committee

I8. Third Committee

19. Mimeographed verbatim records (PVs) of the Plenary meetings of the General Assembly

20. For Fundamental Human Rights

21. Economic and Social Council Official Records

22. Resolutions

23. Report of the Commission on Human Rights (Annual Supplement to Official Records)

24. Mimeographed papers of the Conference on Freedom of Information

25. Mimeographed papers of Committee on Non-Governmental Organizations

26. Documents of the Preparatory Commission of the United Nations and of its Executive Committee

27. Documents of the United Nations Conference on International Organization (San Francisco 1945)

28. United Nations Bulletin

29. United Nations Yearbook

30. Miscellaneous papers and publications of the Department of Public Information of the United Nations Secretariat $\mathrm{x}$

$\mathrm{x}$

$\mathrm{x}$

$\mathrm{x}$ 
no means the only ones which cover the subject, but they are the most important and the student should be guided to them in the fastest and most efficient manner possible.

Thus there will normally be five important items or series cataloged under the heading Human Rights and 25 items or series not so cataloged. This score of five to one against cataloging of this type of material is quantitative but a case can be made for the contention that most of the best material would not be subject cataloged. Evaluation of the 30 items listed above would result in some such standard of relative usefulness to the advanced undergraduate student as is outlined below:

\begin{tabular}{|c|c|c|}
\hline & \multicolumn{2}{|c|}{$\begin{array}{c}\text { Subject } \\
\text { Cataloging }\end{array}$} \\
\hline $\begin{array}{l}\text { A. For Fundamental Human } \\
\text { Rights }\end{array}$ & Yes & No \\
\hline $\begin{array}{l}\text { B. United Nations Yearbook } \\
\text { C. General Assembly Resolu- } \\
\text { tions }\end{array}$ & $\mathbf{x}$ & $\mathbf{x}$ \\
\hline $\begin{array}{l}\text { D. United Nations Bulletin } \\
\text { E. General Assembly Official } \\
\text { Records-Plenary Meet- } \\
\text { ings }\end{array}$ & & $\begin{array}{l}\mathbf{x} \\
\mathbf{x} \\
\mathbf{x}\end{array}$ \\
\hline $\begin{array}{l}\text { F. Mimeographed documents } \\
\text { and summary records of } \\
\text { the Commission on } \mathrm{Hu}- \\
\text { man Rights }\end{array}$ & $x$ & \\
\hline $\begin{array}{l}\text { G. Check list of UN Docu- } \\
\text { ments: Part } 6 \mathrm{D} \text { Commis- } \\
\text { sion on Human Rights } \\
\text { H. General Assembly Official } \\
\text { Records-Third Commit- } \\
\text { tee }\end{array}$ & $\mathbf{x}$ & $\mathbf{x}$ \\
\hline $\begin{array}{l}\text { I. Economic E Social Coun- } \\
\text { cil Resolutions } \\
\text { J. Economic E Social Coun- } \\
\text { cil Official Records }\end{array}$ & & $x$ \\
\hline
\end{tabular}

According to this scale of values, the qualitative measurement of seven to three against cataloging is almost as strong as the quantitative one. This conclusion deter- mined, more than any other factor, the decision not to catalog.

\section{Reference Card File}

The "see also" subject cards are made up at the same time as cards are prepared for the reference card file which is maintained in the collection. This is done by taking the subjects which are used by the United Nations Documents Index in the subject indexes in each of the reference tools. Each such card bears a notation in the lower left hand corner indicating in which reference tool or tools the subject heading appears. A card appearing thus :

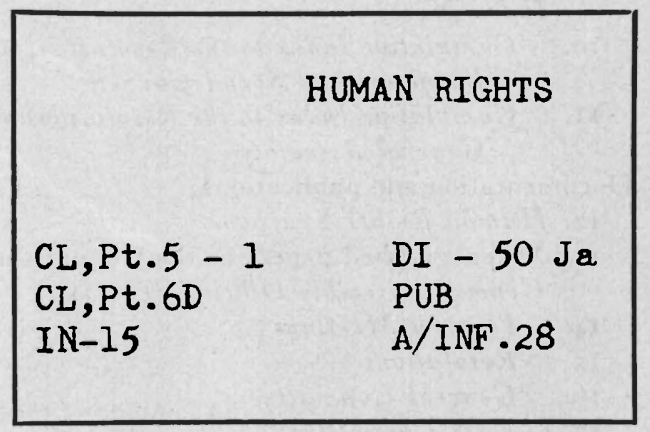

would mean that material on human rights is indexed in the following reference tools:

CL,Pt.5-I Checklist of U.N. Documents, - Part 5 no. I Economic छ Social Council, 1946-1947

CL,Pt.6D Commission on Human Rights, Part 6D

IN-I5 Index Note No. 15, Cumulative Index to the Resolutions of the General Assembly

DI-50 Ja United Nations Documents Index, January, 1950

PUB Publications 1945-1948

A/INF Disposition of Agenda Items of the 3rd Regular Session (of the ' General Assembly)

Anyone engaged in serious research on the subject of "human rights" presents himself to 
the librarian on duty in the collection, having first been referred there by the "see also" card in the catalog. He is then given the various reference tools listed above and the librarian assists him in making his selection of which documents he wishes to consult first.

This type of card is kept in the collection in the reference card file and is the key to the use of the documents therein. As each new reference tool arrives from the United Nations, the staff of the collection add an indication of new material on old subjects by listing a new symbol on the subject cards. These symbols are determined from a master guide and the librarian in charge is the only one authorized to create new symbols, such as the six listed on the sample card above. When a new subject appears, a card is typed bearing that subject and it is taken to Catalog Division of the library where it is either accepted for insertion as a new "see also" card in the catalog or adapted to meet the system of subject headings used by the library. Should the subject chosen by the librarian in the collection not meet the subject cataloging policy of the library, the library policy prevails. However, the collection files its own subject card, under the heading used by the United Nations, with a "see also" card in its reference card file stating that the catalog has material on the particular subject listed under a different heading. This makes it possible to use the subject headings appearing in United Nations documents and cited and quoted in the press and periodicals, without checking and cross checking to find out what the catalog subject heading may be. This practice of having the catalog adhere to the standards of the library profession, and the collection adhere to the United Nations standards, works out well in practice. The staff of the Cataloging Division is thus freed from cluttering up the catalog with innumerable confusing subject headings which apply almost exclusively to the United Nations material and to no other.

The United Nations Documents Index, issued monthly, is checked against the reference card file within 48 hours after receipt, thus assuring that this key guide to the reference tools is as current as physically possible. Any other reference tools received are similarly processed. When the number of symbols at the bottom of any card in the reference card file becomes too numerous for the one card, a second card is made and the first card is retyped to include only the references to the more significant reference tools.

\section{Importance of Trained Staff}

Trained staff is important in the satisfactory maintenance of such a collection and will always be so. However, the procedures described above were designed to make it possible to operate an adequate collection with a nonpermanent staff, that is, with one person who would probably not remain more than three years, supplemented by others who might remain as little as one year. 